\title{
Progression of urothelial carcinoma in situ of the urinary bladder: a switch from luminal to basal phenotype and related therapeutic implications
}

\author{
Isabella Barth ${ }^{1} \cdot$ Ursula Schneider $^{1} \cdot$ Tobias Grimm $^{2} \cdot$ Alexander Karl $^{2} \cdot$ David Horst $^{3} \cdot$ Nadine T. Gaisa $^{1}$. \\ Ruth Knüchel $^{1}$ • Stefan Garczyk ${ }^{1}$
}

Received: 11 January 2018 / Revised: 13 March 2018 / Accepted: 2 April 2018 / Published online: 13 April 2018

(C) The Author(s) 2018

\begin{abstract}
The stratification of bladder cancer into luminal and basal tumors has recently been introduced as a novel prognostic system in patient cohorts of muscle-invasive bladder cancer or high-grade papillary carcinomas. Using a representative immunohistochemistry panel, we analyzed luminal and basal marker expression in a large case series $(n=156)$ of urothelial carcinoma in situ (CIS), a precancerous lesion that frequently progresses to muscle-invasive disease. The majority of CIS cases was characterized by a positivity for luminal markers (aberrant cytokeratin (CK) 20 85\% (132/156), GATA3 median Remmele score (score of staining intensity (0-3) multiplied with percentage of positive cells (0-4)): 12, estrogen receptor (ER) $\beta$ Remmele score $>2$ : 88\% (138/156), human epidermal growth factor receptor 2 (Her2) Dako score $3+32 \%$ (50/156), Her2 Dako score $2+33 \%$ (51/156)), and marginal expression of basal markers (CK5/6+ 2\% (3/156), CK $14+1 \%$ $(2 / 156))$. To further investigate phenotypic stability during disease progression, we compared 48 pairs of CIS and invasive tumors from the same biopsy. A highly significant loss of luminal marker expression $(p<0.001)$ was observed in the course of progression whereas an increase of basal marker expression $(p<0.01)$ was noted in the invasive compartment. Importantly, $91 \%$ of CIS cases demonstrated a positivity for at least one of the two predictive markers Her2 and ER $\beta$, indicating that the analysis of Her2 and ER $\beta$ may help to identify CIS-patient subgroups prone to more efficient targeted treatment strategies. Larger prospective and biomarker-embedded clinical trials are needed to confirm and validate our preliminary findings.
\end{abstract}

Keywords Bladder Cancer · Carcinoma in situ (CIS) · Molecular subtypes $\cdot$ Her2/neu $\cdot$ Estrogen receptor Beta (ER $\beta) \cdot$ Targeted therapy

Ruth Knüchel and Stefan Garczyk contributed equally to this work.

Electronic supplementary material The online version of this article (https://doi.org/10.1007/s00428-018-2354-9) contains supplementary material, which is available to authorized users.

Ruth Knüchel

rknuechel-clarke@ukaachen.de

1 Institute of Pathology, University Hospital RWTH Aachen, Pauwelsstrasse 30, 52074 Aachen, Germany

2 Department of Urology, LMU Munich University, Munich, Marchioninistraße 15, 81377 Munich, Germany

3 Institute of Pathology, LMU Munich University, Munich, Thalkirchner Str. 36, 80337 Munich, Germany

\begin{tabular}{|c|c|}
\hline \multicolumn{2}{|c|}{ Abbreviations } \\
\hline BCG & Bacillus Calmette-Guérin \\
\hline CIS & Carcinoma in situ \\
\hline $\mathrm{CK}$ & Cytokeratin \\
\hline CUETO & Spanish Urological Club for Oncological Treatment \\
\hline EORTC & $\begin{array}{l}\text { European Organization for Research and Treatment } \\
\text { of Cancer }\end{array}$ \\
\hline ER & Estrogen receptor \\
\hline FFPE & Formalin-fixed paraffin-embedded \\
\hline FISH & Fluorescence in situ hybridization \\
\hline Her2 & Human epidermal growth factor receptor type 2 \\
\hline IHC & Immunohistochemistry \\
\hline MIBC & Muscle-invasive bladder cancer \\
\hline MIBC & n-muscle-invasive bladder \\
\hline
\end{tabular}


TMA Tissue microarray

T-DM1 Trastuzumab-DM1

\section{Introduction}

Cancer arising from the urothelium of the bladder is estimated to be the fourth most common malignancy in American men, with an estimated 80,000 new cases in 2017 in the USA [1]. Most bladder carcinomas present as non-muscle-invasive, lowgrade papillary carcinomas and are associated with an excellent prognosis. These tumors recur frequently but rarely progress to muscle-invasive disease. In contrast, muscle-invasive bladder cancer (MIBC) is associated with an unfavorable prognosis (5-year survival $<50 \%)$ due to a high risk of local and systemic disease progression [2]. Most MIBCs arise from carcinoma in situ (CIS), a flat, high-grade, superficial urothelial lesion that is characterized by TP53 mutations and accounts for approximately $10 \%$ of all diagnosed bladder tumors [3]. CIS is considered to be an obligate precancerous lesion, while concomitant CIS is associated with a markedly worse prognosis in patients with bladder cancer, a fact that is mirrored in multiple clinical risk scores (Spanish Urological Club for Oncological Treatment (CUETO), European Organization for Research and Treatment of Cancer (EORTC)) [4].

Therapeutic options for urothelial CIS are limited and based on a moderate to low level of evidence. To inhibit disease progression and recurrence, current guidelines recommend transurethral resection, followed by intravesical instillation of Bacillus Calmette-Guérin (BCG) as first-line therapy $[5,6]$. BCG instillation, however, has numerous side effects, and a high rate of tumors persist or recur irrespective of treatment [7]. In such cases, a radical cystectomy is usually performed, a procedure with high surgical morbidity [8]. Therefore, the need for new and efficient local therapies as well as reliable prognostic and predictive markers are of upmost clinical importance.

A recent stratification of bladder cancer into two main molecular subtypes with prognostic significance- - "luminal" and "basal" - has furthered our understanding of urothelial carcinoma biology [9-12]. Luminal tumors are characterized by the same markers as the differentiated layer of the urothelium, while basal tumors are enriched with squamous markers like CK5 and CK14, typical for undifferentiated basal cells [13]. In MIBC, luminal tumors have a favorable prognosis, while basal carcinomas are associated with advanced cancer stages at diagnosis, with metastatic disease and shorter overall survival [9-12]. Intriguingly, molecular stratification of a large, heterogeneous cohort of early high-grade bladder cancer revealed an inverse correlation between prognosis and molecular subtype, defining the luminal subgroup as the more aggressive one in non-muscle-invasive bladder cancer (NMIBC) [14]. However, only three cases of CIS were included in this study and it remains unclear whether this classification is also applicable in CIS.

Aiming to investigate the role of the recently discovered molecular subtypes of bladder cancer in urothelial CIS, we analyzed luminal and basal marker expression using an established surrogate immunohistochemistry (IHC) panel comprising the luminal markers CK20, GATA3, human epidermal growth factor receptor type 2 (Her2), and estrogen receptor (ER) $\beta$ as well as the basal markers CK5/6 and CK14 in 156 CIS tissue samples from 132 patients. Furthermore, we compared protein expression of these markers in CIS and corresponding invasive tumor parts of the same patient, in an attempt to better understand the stability of a potential subgroup affiliation in the process of stromal invasion.

Moreover, we included two predictive markers and potential treatment targets in our IHC panel, ER $\beta$ and Her2, aiming to evaluate new therapeutic options for urothelial CIS. The significance of ER $\beta$ signaling in urothelial cancer proliferation and the feasibility of ER targeting therapies have been recognized in numerous studies [15-17]. Anti-Her2 therapies are established treatment options in cases of Her2-amplified breast and gastric cancer and have been investigated and proposed as a therapeutic strategy for MIBC [18-20]. To clarify the molecular background of Her2 expression in urothelial CIS, we performed fluorescence in situ hybridization (FISH) in a large fraction of our CIS cohort. We aimed to examine whether protein expression of Her2 and ER $\beta$ may yield conclusive findings on potential therapeutic targets for urothelial CIS.

\section{Materials and methods}

\section{Patients}

One hundred fifty-six samples from 132 patients with urothelial CIS who were treated at the RWTH Aachen University and the LMU Munich University Hospitals between 2004 and 2017 were retrospectively included in this study. Clinicopathological data were obtained and an experienced pathologist (RK) reviewed the histological specimens to confirm the diagnosis. Since it is postulated that flat and papillary lesions develop along different pathways [21], patients with previous or concomitant papillary lesions were excluded from this study. Also, patients with a previous diagnosis of invasion into the lamina propria ( $\geq \mathrm{pT} 1$ ) were not included. This study was conducted at the University Hospital RWTH Aachen in accordance with the requirements of the institutional review board of the RWTH Aachen University (EK 173/06, EK 291/16), the current version of the Declaration of Helsinki, and the good clinical practice guidelines.

For 48 patients, marker expression in cases with CIS and associated concomitant invasive tumor in the same specimen was analyzed. Thorough selection was performed in order to 
assure that the examined CIS was the precursor of the matched invasive tumor, limiting the chance of a secondary tumor cell spread from an invasive carcinoma within the adjacent urothelium. Besides the exclusion of high-grade papillary lesions, only specimens with the same localizations were compared, and only patients with unifocal invasion were included.

\section{Immunohistochemistry}

IHC was performed on frozen and formalin-fixed, paraffinembedded (FFPE) tissue. In 10 cases, the specimens had been stored as frozen samples, which were stained on separate slides. Here, the pre-treatment protocol was $10 \mathrm{~min}$ fixation in $4{ }^{\circ} \mathrm{C}$ acetone, and for ER $\beta$ staining, 30 min fixation in $0.5 \%$ formalin, followed by immersion in $0.1 \%$ triton/ paraformaldehyde.

From 145 FFPE cases of CIS and 48 FFPE cases of concomitant invasive tumor, tissue microarrays (TMAs) were constructed with two punches per case where available [22, 23]. In 84 cases, concomitant normal urothelium from the same time of biopsy was available. Punches of positive and negative controls were placed on the TMAs to reduce experimental variability between staining runs. For pre-treatment, TMA sections $(2 \mu \mathrm{m})$ were incubated in antigen retrieval solution (PT Link, Dako) at $95{ }^{\circ} \mathrm{C}$ for deparaffinization, rehydration, and epitope retrieval. Both slides with cryogenic and slides with FFPE material were then treated with EnVision ${ }^{\mathrm{TM}}$ Flex Solution (Dako) for 5 min to block endogenous peroxidase activity. Immunostaining was performed with antibodies specific for CK20, GATA3, ER $\beta$, Her2, CK5/6, CK14, and p53 (Online Resource 1). Subsequently, tissue sections were incubated with a secondary reagent for $15 \mathrm{~min}$, followed by treatment with a horseradish peroxidase-conjugated polymer (Dako) for $20 \mathrm{~min}$. The peroxidase reaction was visualized with DAB+ Substrate Chromogen System (Dako). The sections were then counterstained with Mayer's hematoxylin.

The percentage of cells positive for markers with a cytoplasmic protein reactivity (CK20, CK5/6, CK14) and for p53 was evaluated. p53 accumulation due to mutation was diagnosed if over $20 \%$ of cells showed intense nuclear staining [24]. Only nuclear positivity for ER $\beta$ and GATA3 was considered relevant and was assessed with an adapted semiquantitative immunoreactive score, as described by Remmele and Stegner, multiplying a score for nuclear staining intensity of positive cells $(0=$ negative, $1=$ weak, $2=$ moderate, $3=$ strong $)$ with the percentage of stained cells $(0=0,1<$ $10 \%, 2=10-50 \%, 3=51-80 \%, 4>80 \%)$. A commonly used threshold considers a cancer "positive" when the Remmele Score is 3-12 [25]. Her2 protein expression was graded according to the DAKO score, an established diagnostic tool in breast cancer, combining staining intensity and percentage of stained cells in a semi-quantitative score from 0 to 1 (negative), 2 (moderate), to 3 (positive, overexpressed) [26]. All stained specimens were manually scored by an experienced pathologist (RK), who was blinded to patient identity.

\section{Fluorescence in situ hybridization}

FISH to identify Her 2 gene amplification was performed according to current ASCO recommendations using the ZytoLight SPEC ERBB2/CEN 17 Dual Color Probe kit (Zytovision) on 126 samples with sufficient material [26]. The test is based on the use of fluorescently labeled oligonucleotide probes specific to the centromeric region of chromosome 17 (CEN17) (ZyOrange) and a sequence within the Her 2 gene locus on chromosome 17 (ZyGreen). The slides were processed according to the manufacturer's protocol: after deparaffinization and rehydration, they were immersed in pretreatment buffer at $98{ }^{\circ} \mathrm{C}$ for $20 \mathrm{~min}$, followed by enzymatic pepsin digestion at $37^{\circ} \mathrm{C}$ for $10 \mathrm{~min}$. This was followed by the application of the Her $2 / C E N 17$ probe, subsequent denaturation at $75{ }^{\circ} \mathrm{C}$, and overnight hybridization at $37{ }^{\circ} \mathrm{C}$. Stringent post-hybridization washes and coating with DAPI solution were performed.

The samples were evaluated by fluorescence microscopy (Axiovert S135 microscope, Zeiss) employing filter sets for DAPI, Spec Green (similar to FITC), and Spec Orange (similar to rhodamine), using Diskus Software (Technisches Büro Hilgers, Germany). Thirty tumor nuclei were analyzed per case, and the ratio of green hybridization signals $(\mathrm{Her} 2)$ over red signals (CEP17) was calculated per cell (Her2/Cep17 ratio). According to ASCO guidelines, the specimen was classified as amplified when the Her $2 / C$ ep 17 ratio was $\geq 2.2$, and polysomy 17 was diagnosed when a mean of $>3$ CEP17 signals per nucleus was determined, a threshold commonly employed in breast cancer [26].

\section{Statistical analysis}

Differential marker expression between CIS and concomitant invasion was assessed using the Wilcoxon matched-pairs signed-rank test in a group of 48 patients. Also, Her2 and ER $\beta$ expression was compared between CIS and normal urothelium in 84 cases with the Wilcoxon matched-pairs signed-rank test. Fisher's exact test was performed in order to correlate FISH results and Her2 IHC Dako score. The level of significance was set to $p<0.05$. Analyses were performed using the SPSS Statistics version 20.0 (IBM, USA) and GraphPad Prism 7.0 (GraphPad Software, USA). All figures were generated using GraphPad Prism 7.0.

\section{Results}

Protein expression of luminal (CK20, GATA3, ER $\beta$, Her2) and basal (CK5/6, CK14) markers as well as of p53 was 
evaluated in 156 CIS specimens from 132 patients ( 104 men and 28 women) using IHC. The median age of the patient cohort was 70 years (range 42-93 years). In 96/156 specimens $(62 \%)$, the patient was untreated prior to the biopsy; in $37 / 156(24 \%)$ cases, the patient had received prior intravesical immunotherapy with BCG; 10/156 (6\%) patients had been treated with mitomycin previously; and 4/ $156(3 \%)$ patients had received both BCG as well as mitomycin before. No pre-treatment data was available in $9 / 156$ $(6 \%)$ cases. In $37 / 156$ cases (24\%), patients presented with pagetoid CIS; in $36 / 156$ cases (23\%), the CIS morphology was denuding, and 10/156 (6\%) of cases showed both growth patterns (Online Resource 2).

The invasive tumor group consisted of 48 cases of CIS with invasion associated in the same specimen. All invasive tumors were high grade (G3), and 7/48 (15\%) were staged pTa, 25/48 (52\%) pT1, 15/48 (31\%) pT2, and 1/48 was staged pT3 (2\%).

\section{Immunohistochemistry}

The majority of CIS cases was characterized by strong positivity for luminal markers: Aberrant positivity for CK20 was detected in 85\% (132/156) of cases, and GATA3 median Remmele score was 12 , with $83 \%(130 / 156)$ of cases scored 12 for GATA3 expression. ER $\beta$ median Remmele score was 12 , and ER $\beta$ positivity (defined as Remmele $>2$ ) was seen in $88 \%$ (138/156) of CIS specimens. Thirty-two percent of cases (50/156) were scored with a Her2 Dako score of 3+, 33\% (51/156) with a Dako score of $2+$, whereas only $2 \%$ of CIS specimens (3/156) exhibited positivity for CK5/6 and 1\% (2/156) for CK 14 . Aberrant p53 expression was seen in 62\% (95/156) of CIS cases (Fig. 1 and Table 1). Expression of the two predictive markers Her2 and ER $\beta$ was analyzed in 84 cases of CIS and normal urothelium from the same specimen and was significantly lower in normal urothelium than in CIS $(p<0.001)$ (median Her2 Dako score 1, median ER $\beta$ Remmele score 6) (Online Resource 3).
Fig. 1 Immunohistochemical staining of carcinoma in situ (CIS) representative of median marker protein expression. a Cytokeratin (CK) 20: $85 \%$ of cases showed aberrant expression. b GATA3: median Remmele score 12. c Human epidermal growth factor receptor 2 (Her2) median Dako score 2, with underlying Her2-negative basal cells. d Estrogen receptor (ER) $\beta$ median Remmele score 12. e CK5/6 $98 \%$ of cases negative, with positivity limited to basal cells only. f CK14 99\% of CIS cases negative. g p53negative CIS ( $38 \%$ of cases). $\mathbf{h}$ p53-positive CIS (62\% of cases). Scale bar $50 \mu \mathrm{m}$
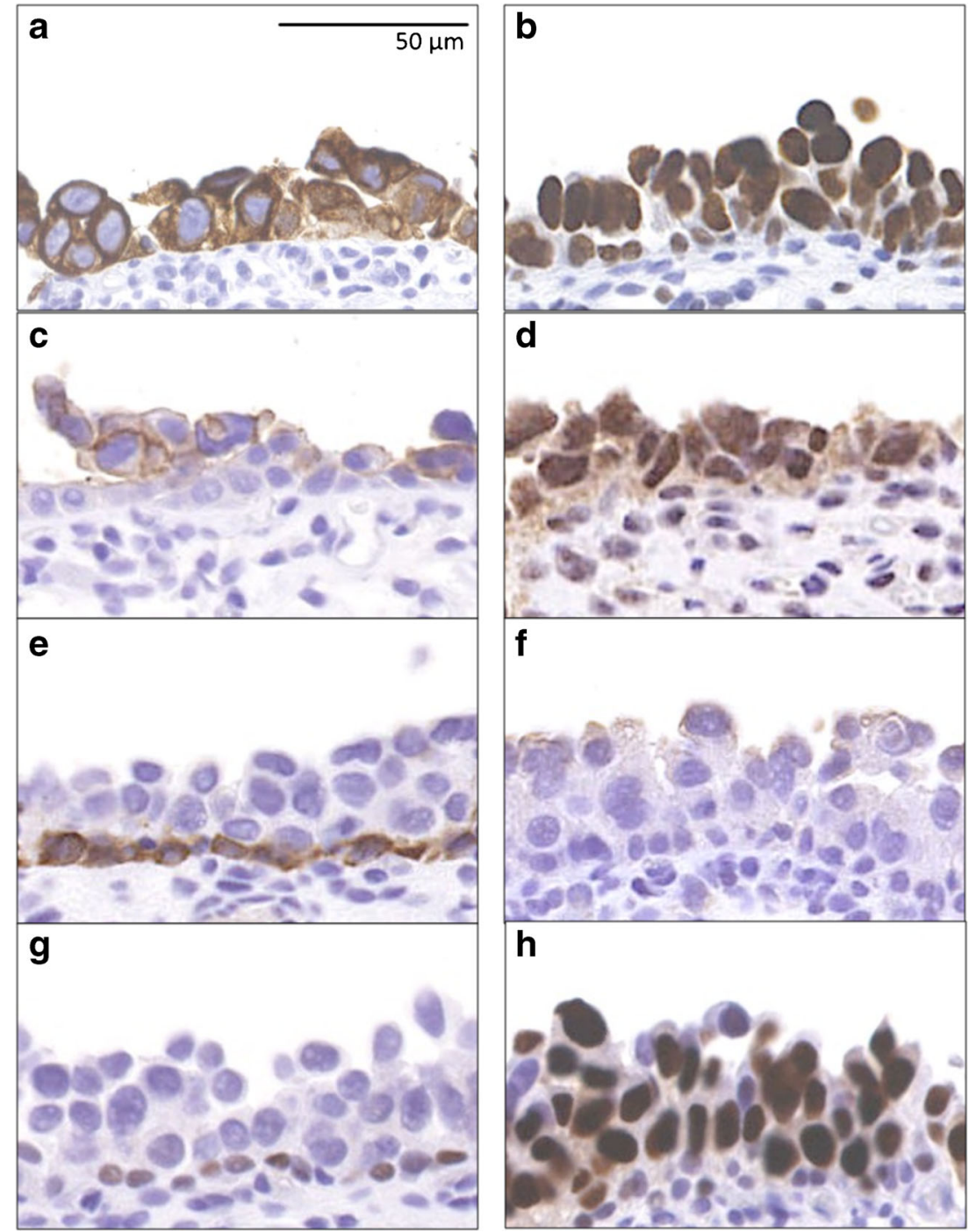
We then compared the expression of luminal and basal markers between CIS and corresponding invasive tumor parts from the same biopsy in 48 patients to investigate the stability of marker expression in the course of progression. The expression of all luminal markers was significantly (for all $p<0.001$ ) downregulated in the invasive compartment, whereas the reactivity of all basal markers localized almost exclusively to the invasive area (for all $p<0.01$ ) (Fig. 2).

\section{Fluorescence in situ hybridization}

FISH was performed in 126 FFPE samples to analyze a potential underlying molecular mechanism of Her2 protein expression. Her 2 amplification was detected in 8/126 (6\%) cases. Mean CEP17 count indicated polysomy 17 in $37 / 126$ (29\%) cases. Her2 protein expression correlated significantly with cases showing polysomy or amplification (Fisher's exact test $p=0.049$ ) (Table 2 and Fig. 3).

\section{Discussion}

In this study, we aimed to elaborate on the affiliation of urothelial CIS to a specific molecular subgroup and to clarify whether molecular subtyping of CIS may also be suitable for prognostic stratification. In this regard, we investigated the immunoreactivity of proteins characteristically expressed in the two intrinsic molecular subsets of bladder cancer [10] and observed that the majority of 156 CIS cases were characterized by the expression of luminal markers and the absence of basal protein expression. In a cohort of 48 patients, we further investigated whether luminal and basal markers remain stable in the course of progression from CIS to invasive disease. Remarkably, we observed that while urothelial CIS strongly and consistently expressed luminal markers, affiliating it to the luminal subtype, this was not the case in the corresponding invasive cells. A significant loss of luminal and a gain of basal marker expression were detected in the invasive compartment.

Data supporting our observation can be extrapolated from recent molecular studies. A strong CIS signature gene expression was found mainly in the basal subgroup of MIBC in the 2017 TCGA dataset, suggesting that these basal tumors evolved from CIS lesions [27]. It was furthermore observed that MIBCs harboring multiple TP53 and RB1 pathway alterations, which are also characteristic for the CIS pathway, are found predominantly in the basal subgroup [10, 13].

The hypothesis of CIS as a precursor lesion of basal muscle-invasive tumors is substantiated by the observation that CIS cells parallel the biology of basal urothelial stem cells. Since urothelial stem cells are capable of sustaining long-term growth and proliferation, it is probable that their longevity makes them the most susceptible to the
Table 1 Protein expression of luminal and basal markers in CIS

\begin{tabular}{lll}
\hline & $\begin{array}{l}\text { All CIS cases } \\
n=156(100 \%)\end{array}$ & Median \\
\hline CK20 & $132(85 \%)$ & Positive \\
Positive & $24(15 \%)$ & \\
Negative & & 2 \\
Her2 & $55(35 \%)$ & \\
$0-1$ & $51(33 \%)$ & 12 \\
2 & $50(32 \%)$ & \\
3 & & \\
ER $\beta$ & $18(12 \%)$ & \\
$0-2$ & $138(88 \%)$ & \\
$3-12$ & & \\
GATA3 & $5(3 \%)$ & Negative \\
$0-2$ & $151(97 \%)$ & \\
$3-12$ & & \\
CK5/6 & $3(2 \%)$ & \\
Positive & $153(98 \%)$ & \\
Negative & & \\
CK14 & $2(1 \%)$ & \\
Positive & $154(99 \%)$ & \\
Negative & & \\
\hline
\end{tabular}

Overview of protein expression of luminal and basal markers in a cohort of 156 CIS cases. Cytokeratin (CK) 20, GATA3, human epidermal growth factor receptor 2 (Her2), and estrogen receptor (ER) $\beta$ are luminal markers; CK5/6 and CK14 are basal markers. For CK 20, CK5/6, and CK14, percentage of positive cells was determined, and tumors were considered positive if $>50 \%$ of cells expressed the CK. GATA3 expression was scored with the Dako score; Her2 and ER $\beta$ expression was scored with the Remmele score

accumulation of oncogenic hits and therefore multistep carcinogenesis [28].

At the same time, molecular evidence underlines the affiliation of CIS to a luminal subgroup. Hedegaard et al. conducted expression profiling of NMIBC, discovering that cases overexpressing the above-mentioned CIS gene signature belonged to the luminal-like group ("class 2"), with high levels of luminal (CK20) and low levels of basal (CK5) markers. As the study only included three CIS cases, we consider our significantly larger cohort a possible endorsement of these data [14]. The underlying mechanisms causing CIS cells to consistently express luminal markers, as well as the stimuli inducing the basal protein expression in invasive cells of CIS origin, remain to be explored.

Only minor advances towards more efficient and targeted intravesical therapies for urothelial CIS have been made in the last decades [29]. At the time of initial diagnosis, an organsparing approach of transurethral resection and BCG instillation is usually chosen [30]. The latter in particular is associated with severe morbidity and a high probability of so-called BCG failure, including disease progression and recurrence [31]. The risk of tumor progression to a life-threatening 
Fig. 2 Marker expression of CIS and concomitant invasive tumor. a Cytokeratin (CK) 20 (percentage of positive cells evaluated). b GATA3 (Remmele Score). c Human epidermal growth factor receptor 2 (Her2) (DAKO Score). d Estrogen Receptor (ER) $\beta$ (Remmele Score). e CK5/6 (percentage of positive cells). f CK14 (percentage of positive cells). Band indicates median, bottom, and top of box show first and third quartiles, whiskers demonstrate range of data distribution (minimum/maximum). A significant downregulation of luminal markers and an upregulation of basal markers were observed in the invasive compartment
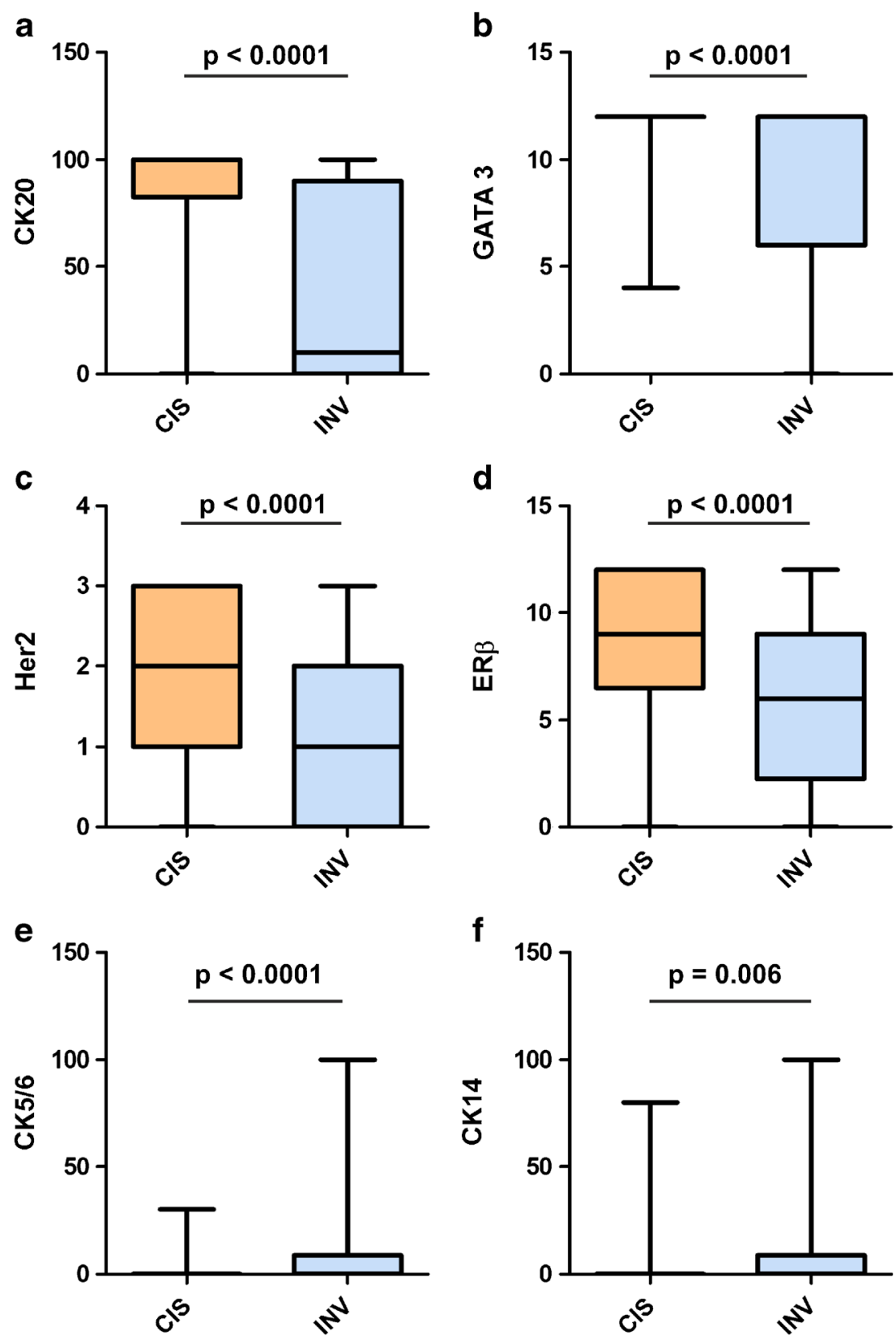

muscle-invasive situation encourages clinicians to recommend radical cystectomy in patients with extensive or recurrent CIS. This procedure is on the one hand associated with an excellent tumor-specific survival [32], but on the other hand bears a significant risk of overtreatment and associated surgical morbidity [8, 33]. Clinical and preclinical work on new therapeutic targets in bladder cancer has mainly focused on MIBC [34], and few authors have examined new therapeutic targets in urothelial CIS [29].

Two markers from our luminal panel, Her2 and ER, are well-established predictive markers and therapeutic targets in other tumor entities $[35,36]$. We aimed to evaluate the therapeutic potential of Her 2 and ER $\beta$ in urothelial CIS by assessing protein expression of both markers, as well as the molecular background of Her2 expression by FISH analysis.

Two ERs exist in the human body, ER $\alpha$ and $\beta$, which mediate ligand-dependent transactivation of gene expression [37]. Not only is ER $\beta$ the predominant ER in the bladder with a potential prognostic role in NMIBC, but it is also postulated to promote cancer growth and progression [16]. Multiple studies have investigated ER $\beta$ protein expression in both normal urothelium as well as urothelial carcinoma [16, 17, 38]; however, to the best of our knowledge, none of these included CIS. Our analyses showed ER $\beta$ positivity in $88 \%$ (138/156) of CIS cases. 
Table 2 Dako score results for 126 CIS cases analyzed by Her2 FISH

\begin{tabular}{lllll}
\hline Dako score & & $0,1+$ & $2+$ & $3+$ \\
\hline Neutral & $n=81$ & 33 & 29 & 19 \\
Polysomy 17 & $n=37$ & 8 & 11 & 18 \\
Her2-amplified & $n=8$ & 2 & 1 & 5 \\
\hline
\end{tabular}

Fluorescence in situ hybridization (FISH) results and immunohistochemical (IHC) staining (Dako score 0-3+) for Her2, showing the distribution of neutral (non-polysomic, non-Her2-amplified), chromosome 17 polysomic, and Her2-amplified cases in the different IHC categories

ER $\beta$ has previously been identified as a druggable target in bladder cancer using the selective ER modulator Raloxifene or ER $\beta$-specific antagonists such as PHTPP $[16,35]$. Furthermore, current evidence suggests that ER $\beta$ plays a central role in the proliferative and invasive potential of bladder cancer cells and therefore may present a promising target for selective ER $\beta$ inhibitors [39]. As such, the observed ER $\beta$ positivity in the majority of CIS cases in our cohort warrants further investigation of $E R \beta$ as a potential target in early, flat, high-grade bladder cancer.

The other marker with therapeutic potential included in our IHC panel is Her2, a member of the epidermal growth factor receptor family, which, when overexpressed, enhances proliferation, cell survival, and the invasive capacity of tumor cells [40, 41]. Anti-Her2 therapy has emerged as the mainstay of treatment in Her2-amplified breast and gastric cancer $[18,20]$. Conflicting findings have been reported on the rate and the mechanism of Her2 overexpression in
MIBC, which, after breast and gastric cancer, shows the highest rate of Her2 amplification [13]. A recent investigation of the mechanism of Her2 expression in MIBC showed that Her2 protein overexpression arises from various mechanisms, including gene amplification [42]. Though Her2 immunostaining has previously been investigated as a diagnostic tool for urothelial CIS [43], our study is the first to examine Her2 expression in a significantly larger patient cohort and the first to investigate the possible genetic background of Her2 expression in CIS. IHC characterized 52 cases $(33 \%)$ as Her2 moderate $(2+)$ and 50 cases $(32 \%)$ as Her2 positive $(3+)$.

FISH analysis detected only a low rate of Her 2 amplifications in $8 / 126$ cases $(6 \%)$. At the same time, we observed polysomy 17 , indicated by an elevated CEP17 count, in 37/ $126(29 \%)$ of cases. We observed a significantly higher Her2 expression in cases with polysomy 17 or Her2 amplification, compared to CIS cases without these alterations. Chromosome 17 polysomy has been previously described as one of the mechanisms driving Her2 expression in breast cancer, especially in tumors with IHC 2+ scores [44]. Interestingly, various studies support the effectivity of trastuzumab, a humanized anti-HER2 monoclonal antibody, in polysomic, non-amplified breast cancer [45, 46].

Although none are currently in clinical use for bladder cancer, there is accumulating evidence that anti-Her2targeted therapies are promising novel treatment strategies in urothelial carcinoma [42]. As the driver status of Her2, even in Her2-overexpressing or Her2-amplified bladder cancer cases, is difficult to predict without detailed
Fig. 3 Fluorescence in situ hybridization (FISH). a Neutral (non-amplified, non-polysomic). b Polysomy 17. c Her2 amplification. d Distribution of Her2-amplified (Amp), chromosome 17 polysomic, and neutral cases among the various Her2 protein-staining intensities, measured by Dako score. Red hybridization signals indicate the centromeric region of chromosome 17; green signals bind to the Her2 gene locus on chromosome 17
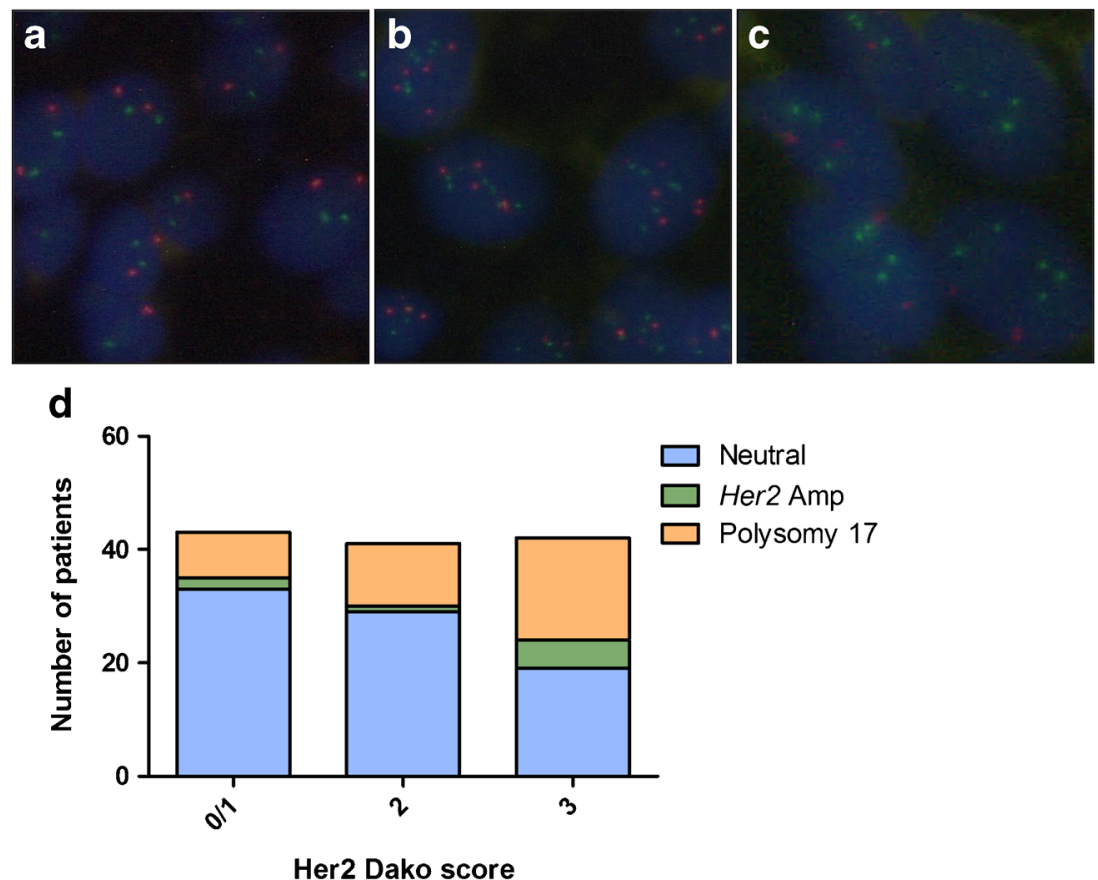
genome-wide analyses [42], we propose the use of agents whose impact is independent of Her2-signaling inhibition. Targeting Her2-overexpressing cells via antibody-mediated cytotoxicity of clinically established monoclonal antibodies like trastuzumab or the cytotoxic effects of the emerging antibody-drug conjugate trastuzumab-DM1 (T-DM1) may be a viable option [36, 47]. We see particular potential for clinical studies investigating the response rate of an intravesical combination therapy of BCG and T-DM1. Furthermore, the large number of patients with BCGrefractory CIS may benefit from a Her2 targeting, which would provide a bladder-sparing approach for patients otherwise subjected to cystectomy.

We are aware of the limitations of this retrospective study. Firstly, the observations from this study need to be validated in independent patient cohorts, possibly with an expansion to other superficial urothelial cancers, such as non-invasive papillary high-grade tumors. Secondly, further molecular studies are needed to explain the phenomenon of the observed marker switch from luminal to basal in the course of invasion. Thirdly, the possible targets identified in this study, ER $\beta$ and Her2, belong to the luminal marker panel, which is downregulated in the process of invasion, possibly limiting the suitability of ER $\beta$ and Her2 targeting to CIS and should encourage combined therapy modalities.

None withstanding the aforementioned limitations, we have for the first time reported on a shift from luminal to basal marker expression in urothelial carcinoma and distinguished two potential therapeutic targets in CIS. In summary, positivity for either ER $\beta$, Her2, or both proteins was observed in 91\% (142/156) of CIS cases, while normal urothelium showed significantly lower expression of both markers, highlighting their potential for clinical use. The protein targets identified in this study, Her2 and ER $\beta$, may be amenable to targeted intravesical therapies in early-stage, high-grade bladder cancer. As mentioned above, validation in an independent cohort of patients and clinical trials are required to confirm our preliminary findings.

Acknowledgements This research project is supported by the STARTProgram of the Faculty of Medicine, RWTH Aachen. Part of the data of this research project was presented at the " $9^{\text {th }}$ AUF Symposium 2017" (German Urologic Society) and awarded with the presentation prize.

Author's contributions I.B. collected the clinical patient data, performed the experiments (TMA construction, IHC staining, FISH), evaluated the FISH data, assisted in the histopathological examinations, analyzed the data, participated in the study design, and wrote the manuscript. U.S. assisted in carrying out experiments. T.G. and A.K. assisted in clinical data acquisition. D.H. assisted in pathological data acquisition. N.T.G. assisted in the histopathological examinations. R.K. stimulated the study, provided the reference pathology for all the samples used, and revised the manuscript. S.G. conceived the study, analyzed the data, and drafted and revised the manuscript.

\section{Compliance with ethical standards}

All patients gave informed consent for retention and anonymous analysis of their tissue for research purposes in accordance with the requirements of the institutional review board of the medical faculty of the RWTH Aachen University (EK 173/06, EK 291/16).

Conflict of interest The authors declare that they have no conflict of interest.

Open Access This article is distributed under the terms of the Creative Commons Attribution 4.0 International License (http:// creativecommons.org/licenses/by/4.0/), which permits unrestricted use, distribution, and reproduction in any medium, provided you give appropriate credit to the original author(s) and the source, provide a link to the Creative Commons license, and indicate if changes were made.

\section{References}

1. Siegel RL, Miller KD, Jemal A (2017) Cancer statistics. CA Cancer J Clin 67:7-30

2. Knowles MA, Hurst CD (2015) Molecular biology of bladder cancer: new insights into pathogenesis and clinical diversity. Nat Rev Cancer 15:25-41

3. Kirkali Z, Chan T, Manoharan M, Algaba F, Busch C, Cheng L, Kiemeney L, Kriegmair M, Montironi R, Murphy WM, Sesterhenn IA, Tachibana M, Weider J (2005) Bladder cancer: epidemiology, staging and grading, and diagnosis. Urology 66:4-34

4. Holz S, Albisinni S, Gilsoul J, Pirson M, Duthie V, Quackels T, vanden Bossche M, Roumeguère T (2017) Risk factor assessment in high-risk, bacillus Calmette-Guerin-treated, non-muscle-invasive bladder cancer. Res Rep Urol 9:195-202

5. Chang SS, Boorjian SA, Chou R, Clark PE, Daneshmand S, Konety BR, Pruthi R, Quale DZ, Ritch CR, Seigne JD, Skinner EC, Smith ND, McKiernan JM (2016) Diagnosis and treatment of non-muscle invasive bladder cancer: AUA/SUO guideline. J Urol 196:1021-1029

6. Lerner SP, Bajorin DF, Dinney CP, Efstathiou JA, Groshen S, Hahn NM, Hansel D, Kwiatkowski D, O’Donnell M, Rosenberg J, Svatek R, Abrams JS, al-Ahmadie H, Apolo AB, Bellmunt J, Callahan M, Cha EK, Drake C, Jarow J, Kamat A, Kim W, Knowles M, Mann B, Marchionni L, McConkey D, McShane L, Ramirez N, Sharabi A, Sharpe AH, Solit D, Tangen CM, Amiri AT, van Allen E, West PJ, Witjes JA, Quale DZ (2016) Summary and recommendations from the National Cancer Institute's clinical trials planning meeting on novel therapeutics for non-muscle invasive bladder cancer. Bladder Cancer 2:165-202

7. Jakse G, Hall R, Bono A, H\&ouml; Itl W, Carpentier P, Spaander JP, van der Meijden APM, Sylvester R (2001) Intravesical BCG in patients with carcinoma in situ of the urinary bladder: long-term results of EORTC GU Group phase II protocol 30861. Eur Urol 40: 144-150

8. Shabsigh A, Korets R, Vora KC, Brooks CM, Cronin AM, Savage C, Raj G, Bochner BH, Dalbagni G, Herr HW, Donat SM (2009) Defining early morbidity of radical cystectomy for patients with bladder cancer using a standardized reporting methodology. Eur Urol 55:164-174

9. Choi W, Porten S, Kim S, Willis D, Plimack ER, Hoffman-Censits J, Roth B, Cheng T, Tran M, Lee IL, Melquist J, Bondaruk J, Majewski T, Zhang S, Pretzsch S, Baggerly K, Siefker-Radtke A, Czerniak B, Dinney CPN, McConkey DJ (2014) Identification of distinct basal and luminal subtypes of muscle-invasive bladder 
cancer with different sensitivities to frontline chemotherapy. Cancer Cell 25:152-165

10. Damrauer JS, Hoadley KA, Chism DD, Fan C, Tiganelli CJ, Wobker SE, Yeh JJ, Milowsky MI, Iyer G, Parker JS, Kim WY (2014) Intrinsic subtypes of high-grade bladder cancer reflect the hallmarks of breast cancer biology. Proc Natl Acad Sci U S A 111: 3110-3115

11. Ochoa AE, Choi W, Su X, Siefker-Radtke A, Czerniak B, Dinney C, McConkey D (2016) Specific micro-RNA expression patterns distinguish the basal and luminal subtypes of muscle-invasive bladder cancer. Oncotarget 7:80164-80174

12. Sjodahl G, Lauss M, Lovgren K, Chebil G, Gudjonsson S, Veerla S, Patschan O, Aine M, Ferno M, Ringner M, Mansson W, Liedberg F, Lindgren D, Hoglund M (2012) A molecular taxonomy for urothelial carcinoma. Clin Cancer Res 18:3377-3386

13. The Cancer Genome Atlas Research Network (2014) Comprehensive molecular characterization of urothelial bladder carcinoma. Nature 507:315-322

14. Hedegaard J, Lamy P, Nordentoft I, Algaba F, Høyer S, Ulhøi BP, Vang S, Reinert T, Hermann GG, Mogensen K, Thomsen MBH, Nielsen MM, Marquez M, Segersten U, Aine M, Höglund M, Birkenkamp-Demtröder K, Fristrup N, Borre M, Hartmann A, Stöhr R, Wach S, Keck B, Seitz AK, Nawroth R, Maurer T, Tulic C, Simic T, Junker K, Horstmann M, Harving N, Petersen AC, Calle ML, Steyerberg EW, Beukers W, van Kessel KEM, Jensen JB, Pedersen JS, Malmström PU, Malats N, Real FX, Zwarthoff EC, Ørntoft TF, Dyrskjøt L (2016) Comprehensive transcriptional analysis of early-stage urothelial carcinoma. Cancer Cell 30:27-42

15. Han B, Cui D, Jing Y, Hong Y, Xia S (2012) Estrogen receptor beta (ERbeta) is a novel prognostic marker of recurrence survival in nonmuscle-invasive bladder cancer potentially by inhibiting cadherin switch. World J Urol 30:861-867

16. Hsu I, Vitkus S, Da J, Yeh S (2013) Role of oestrogen receptors in bladder cancer development. Nat Rev Urol 10:317-326

17. Shen SS, Smith CL, Hsieh JT, Yu J, Kim IY, Jian W, Sonpavde G, Ayala GE, Younes M, Lerner SP (2006) Expression of estrogen receptors-alpha and -beta in bladder cancer cell lines and human bladder tumor tissue. Cancer 106:2610-2616

18. Slamon DJ, Clark GM, Wong SG, Levin W, Ullrich A, McGuire W (1987) Human breast cancer: correlation of relapse and survival with amplification of the HER-2/neu oncogene. Science 235:177182

19. Gravalos C, Jimeno A (2008) HER2 in gastric cancer: a new prognostic factor and a novel therapeutic target. Ann Oncol 19:15231529

20. Bang YJ, Van Cutsem E, Feyereislova A et al (2010) Trastuzumab in combination with chemotherapy versus chemotherapy alone for treatment of HER2-positive advanced gastric or gastro-oesophageal junction cancer (ToGA): a phase 3, open-label, randomised controlled trial. Lancet 376:687-697

21. Spruck CH 3rd, Ohneseit PF, Gonzalez-Zulueta M et al (1994) Two molecular pathways to transitional cell carcinoma of the bladder. Cancer Res 54:784-788

22. Kononen J, Bubendorf L, Kallioniemi A et al (1998) Tissue microarrays for high-throughput molecular profiling of tumor specimens. Nat Med 4:844-847

23. Schraml P, Kononen J, Bubendorf L, Moch H, Bissig H, Nocito A, Mihatsch MJ, Kallioniemi OP, Sauter G (1999) Tissue microarrays for gene amplification surveys in many different tumor types. Clin Cancer Res 5:1966-1975

24. Slaton JW, Benedict WF, Dinney CP (2001) P53 in bladder cancer: mechanism of action, prognostic value, and target for therapy. Urology 57:852-859

25. Remmele W, Stegner HE (1987) Recommendation for uniform definition of an immunoreactive score (IRS) for immunohistochemical estrogen receptor detection (ER-ICA) in breast cancer tissue. Pathologe 8:138-140

26. Wolff AC, Hammond ME, Hicks DG, Dowsett M, McShane L, Allison KH, Allred DC, Bartlett JM, Bilous M, Fitzgibbons P, Hanna W, Jenkins RB, Mangu PB, Paik S, Perez EA, Press MF, Spears PA, Vance GH, Viale G, Hayes DF, American Society of Clinical Oncology, College of American Pathologists (2013) Recommendations for human epidermal growth factor receptor 2 testing in breast cancer: American Society of Clinical Oncology/ College of American Pathologists clinical practice guideline update. J Clin Oncol 31:3997-4013

27. Robertson AG, Kim J, Al-Ahmadie H et al (2017) Comprehensive molecular characterization of muscle-invasive bladder cancer. Cell 171:540-556.e525

28. Brandt WD, Matsui W, Rosenberg JE, He X, Ling S, Schaeffer EM, Berman DM (2009) Urothelial carcinoma: stem cells on the edge. Cancer Metastasis Rev 28:291-304

29. Tang DH, Chang SS (2015) Management of carcinoma in situ of the bladder: best practice and recent developments. Ther Adv Urol 7: 351-364

30. Woldu SL, Bagrodia A, Lotan Y (2017) Guideline of guidelines: non-muscle-invasive bladder cancer. BJU Int 119:371-380

31. Brausi M, Oddens J, Sylvester R, Bono A, van de Beek C, van Andel G, Gontero P, Turkeri L, Marreaud S, Collette S, Oosterlinck W (2014) Side effects of Bacillus Calmette-Guerin (BCG) in the treatment of intermediate- and high-risk Ta, T1 papillary carcinoma of the bladder: results of the EORTC genitourinary cancers group randomised phase 3 study comparing onethird dose with full dose and 1 year with 3 years of maintenance BCG. Eur Urol 65:69-76

32. Huguet J, Crego M, Sabate S et al (2005) Cystectomy in patients with high risk superficial bladder tumors who fail intravesical BCG therapy: pre-cystectomy prostate involvement as a prognostic factor. Eur Urol 48:53-59 discussion 59

33. Sylvester RJ, van der Meijden A, Witjes JA, Jakse G, Nonomura N, Cheng C, Torres A, Watson R, Kurth KH (2005) High-grade Ta urothelial carcinoma and carcinoma in situ of the bladder. Urology 66:90-107

34. Sanli O, Dobruch J, Knowles MA (2017) Bladder cancer. Nat Rev Dis Primers 3:17022

35. Kim HT, Kim BC, Kim IY, Mamura M, Seong DH, Jang JJ, Kim SJ (2002) Raloxifene, a mixed estrogen agonist/antagonist, induces apoptosis through cleavage of BAD in TSU-PR1 human cancer cells. J Biol Chem 277:32510-32515

36. Hudis CA (2007) Trastuzumab - mechanism of action and use in clinical practice. N Engl J Med 357:39-51

37. Cowley SM, Hoare S, Mosselman S, Parker MG (1997) Estrogen receptors alpha and beta form heterodimers on DNA. J Biol Chem 272:19858-19862

38. Miyamoto H, Yao JL, Chaux A, Zheng Y, Hsu I, Izumi K, Chang C, Messing EM, Netto GJ, Yeh S (2012) Expression of androgen and oestrogen receptors and its prognostic significance in urothelial neoplasm of the urinary bladder. BJU Int 109:1716-1726

39. Hsu I, Chuang KL, Slavin S, da J, Lim WX, Pang ST, O'Brien JH, Yeh S (2014) Suppression of ERbeta signaling via ERbeta knockout or antagonist protects against bladder cancer development. Carcinogenesis 35:651-661

40. Yarden Y, Sliwkowski MX (2001) Untangling the ErbB signalling network. Nat Rev Mol Cell Biol 2:127-137

41. Schechter AL, Stern DF, Vaidyanathan L, Decker SJ, Drebin JA, Greene MI, Weinberg RA (1984) The neu oncogene: an erb-Brelated gene encoding a $185,000-\mathrm{Mr}$ tumour antigen. Nature 312 : 513-516

42. Kiss B, Wyatt AW, Douglas J, Skuginna V, Mo F, Anderson S, Rotzer D, Fleischmann A, Genitsch V, Hayashi T, Neuenschwander M, Buerki C, Davicioni E, Collins C, Thalmann 
GN, Black PC, Seiler R (2017) Her2 alterations in muscle-invasive bladder cancer: patient selection beyond protein expression for targeted therapy. Sci Rep 7:42713

43. Jung S, Wu C, Eslami Z, Tanguay S, Aprikian A, Kassouf W, Brimo F (2014) The role of immunohistochemistry in the diagnosis of flat urothelial lesions: a study using CK20, CK5/6, P53, Cd138, and Her2/Neu. Ann Diagn Pathol 18:27-32

44. Hanna WM, Ruschoff J, Bilous M et al (2014) HER2 in situ hybridization in breast cancer: clinical implications of polysomy 17 and genetic heterogeneity. Mod Pathol 27:4-18

45. Hofmann M, Stoss O, Gaiser T, Kneitz H, Heinmöller P, Gutjahr T, Kaufmann M, Henkel T, Rüschoff J (2008) Central HER2 IHC and FISH analysis in a trastuzumab (Herceptin) phase II monotherapy study: assessment of test sensitivity and impact of chromosome 17 polysomy. J Clin Pathol 61:89-94

46. Kaufman PA, Broadwater G, Lezon-Geyda K et al (2007) CALGB 150002: correlation of HER2 and chromosome 17 (ch17) copy number with trastuzumab (T) efficacy in CALGB 9840, paclitaxel (P) with or without T in HER2+ and HER2- metastatic breast cancer (MBC). J Clin Oncol 25:1009-1009

47. Lewis Phillips GD, Li G, Dugger DL, Crocker LM, Parsons KL, Mai E, Blattler WA, Lambert JM, Chari RVJ, Lutz RJ, Wong WLT, Jacobson FS, Koeppen H, Schwall RH, Kenkare-Mitra SR, Spencer SD, Sliwkowski MX (2008) Targeting HER2-positive breast cancer with trastuzumab-DM1, an antibody-cytotoxic drug conjugate. Cancer Res 68:9280-9290 